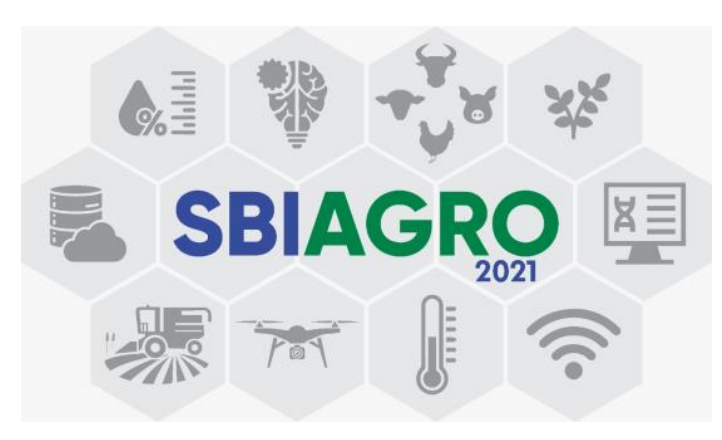

\title{
Classificação climática de thornthwaite (1948) para a região Centro-Oeste: uma abordagem inédita para a maior região produtora de grãos do Brasil
}

\author{
Rafael F. Lima ${ }^{1}$, Lucas E. O. Aparecido ${ }^{2}$, Guilherme B. Torsoni ${ }^{3}$, Gabriel H. O. \\ Souza $^{1}$ \\ ${ }^{1}$ Departamento de Agronomia - Instituto Federal de Mato Grosso do Sul (IFMS) - \\ Naviraí - MS - Brasil \\ ${ }^{2}$ Departamento de Agronomia - Instituto Federal de Mato Grosso do Sul (IFMS) - \\ Naviraí - MS - Brasil \\ ${ }^{3}$ Departamento de Física - Instituto Federal de Mato Grosso do Sul (IFMS) - Naviraí - \\ MS - Brasil \\ rafael.lima2@estudante.ifms.edu.br, lucas.aparecido@ifms.edu.br, \\ guilherme.torsonidifms.edu.br, gabriel.souza4@estudante.ifms.edu.br
}

\begin{abstract}
A simple way to capture climate variation over a location is through the use of climate classification systems. Thus, the objective of this work is to classify the climate of the Central-West region of Brazil using Thornthwaite's (1948) climate classification system. Climatic data from the NASA / POWER station were collected daily in the period 1990 - 2020, where potential evapotranspiration and the climatological water balance were calculated. The climatic classification was generated by the Thornthwaite system (1948). Twenty-four climate classes were obtained for the entire study region, with the most predominant classes being ArA' $a^{\prime}$ and B1rA' $a^{\prime}$ with $15.0 \%$ and $12.5 \%$ respectively.
\end{abstract}

Resumo. Uma forma simples de captar a variação do clima sobre um local é através do uso de sistemas de classificação climática. Dessa forma o objetivo desse trabalho é classificar o clima da região Centro-Oeste do Brasil utilizando o sistema de classificação climática de Thornthwaite (1948). Foram coletados dados climáticos da estação NASA / POWER de forma diária no período de 1990 - 2020, onde foram calculados a evapotranspiração potencial e o balanço hídrico climatológico. A classificação climática foi gerada pelo sistema de Thornthwaite (1948). Foram obtidas 24 classes 
climáticas para toda a região de estudo, sendo as classes mais predominantes a ArA'a' $^{\prime}$ e B1rA'a' com $15,0 \%$ e $12,5 \%$ respectivamente.

\section{Introdução}

Buscando uma forma simplificada para analisar características climáticas de um determinado local, a classificação climática surge afim de sintetizar e agrupar elementos climáticos comuns em tipos climáticos, delimitando espacialmente regiões climáticas homogêneas [Tapiador et al. 2019]. Os sistemas de classificação climática são compostos por métodos estatísticos eficientes para capturar informações climáticas, gerando um arranjo eficiente de informações de uma forma simples e generalizada [Baker et al. 2010].

Na classificação climática elaborada por Thornthwaite, a planta é vista como um meio físico capaz de retirar umidade do solo e transferir para o sistema atmosférico através de processos fisiológicos, sendo esse sistema mais indicado para fins agrícolas [Elguindi et al. 2014]. A variabilidade do clima influencia diretamente na produção agrícola, afetando o desenvolvimento e a produtividade das lavouras.

No Brasil, a região Centro-Oeste se destaca na produção de diversas comoditys do agronegócio sendo elas: Soja, Milho, e algodão [Conab 2021]. Assim, buscou-se com o trabalho classificar o clima da região Centro-Oeste do Brasil utilizando o sistema de classificação climática de Thornthwaite (1948).

\section{Material e métodos}

Foram coletados dados climáticos de temperatura média do ar em graus celsius $\left({ }^{\circ} \mathrm{C}\right) \mathrm{e}$ precipitação em milímetros $(\mathrm{mm})$ de forma diária para 467 municípios localizados na região Centro-Oeste do Brasil no período de 1990 - 2020, obtidos pela plataforma National Aeronautics and Space Administration / Prediction of Worldwide Energy Resources - NASA / POWER. Essa plataforma disponibiliza dados meteorológicos modelados por satélite com resolução espacial de $1^{\circ}$ (latitude - longitude) [Stackhouse et al. 2015].

A evapotranspiração potencial $(\mathrm{mm})$ foi calculada pelo método de Camargo (1971) e o balanço hídrico climatológico (BHC) foi gerado para todas as localidades estudadas seguindo a metodologia de Thornthwaite e Mather (1955), utilizando uma capacidade de água disponível no solo igual $100 \mathrm{~mm}$. A classificação climática foi realizada pelo método proposto por Thornthwaite (1948), utilizando os atributos de deficiência hídrica $(\mathrm{mm})$ e excedente hídrico $(\mathrm{mm})$ obtidos do extrato do BHC associados a evapotranspiração potencial [Rolim e Aparecido 2016].

Com a utilização de um sistema de informações geográficas (SIG) foi realizado a espacialização dos atributos climáticos utilizando krigagem ordinária com um modelo esférico [Krige 1951], e através da sobreposição dos mapas foi obtido a delimitação espacial para as classes climáticas de Thornthwaite (1948).

\section{Resultados e discussões}

A região Centro-Oeste apresentou predomínio de 6 tipos climáticos (Figura 1) sendo eles A (Super úmido), B1 (úmido), B2 (úmido), B3 (úmido), B4 (úmido) e C2 (Subúmido). Foram encontradas 24 classes climáticas de Thornthwaite (1948), fator 
determinado pela alta especificidade do sistema em captar variações mínimas nos atributos climáticos da região (Figura 1). Os tipos climáticos com maior destaque na região foram B2 (úmido) e B3 (úmido) com ocorrência de 6 classes climáticas em cada.

As classes ArA'a' e B1rA'a' (Figura 1) foram mais expressivas representando $15,0 \%$ e $12,5 \%$ da região de estudo respectivamente. A classe C2rA'a' (Figura 1) apresentou maior predomínio no bioma pantaneiro caracterizando a região como clima Sub-úmido com pouca deficiência hídrica, evapotranspiração acima $1140 \mathrm{~mm}$ anuais (megatérmico) sendo $48 \%$ concentrados na estação do verão. O bioma pantaneiro corresponde a uma extensa superfície alagada, considerada a maior planície alagada do mundo [Cardoso e Marcuzzo 2010]. As classes B1rA'a' e B2rA'a' (Figura 1) representam grande parte das regiões agrícolas do Mato Grosso do Sul.

Localidades ao norte do Estado do Mato Grosso apresentaram predomínio das classes ArA'a' e AwA'a' (Figura 1) caracterizando a região como clima superúmido com moderada deficiência hídrica no verão, evapotranspiração acima $1140 \mathrm{~mm}$ anuais (megatérmico) sendo $48 \%$ concentrados na estação do verão. Essas localidades apresentam altos índices de precipitação anual, pouca deficiência hídrica e temperaturas mais elevadas, principalmente no verão. As altas temperaturas no verão podem influenciar negativamente as lavouras de soja, provocando o abortamento de vagens causado pelo estresse térmico [Djanaguiraman et al. 2019]

No Distrito federal, a classe predominante foi a B2wB'3a' (Figura1). As regiões sul de Goiás e do Mato Grosso do Sul apresentaram desenvolvimento em comum da classe climática B2rB'4a' (Figura 1). Essas localidades apresentam temperatura do ar e índices pluviométricos semelhantes.

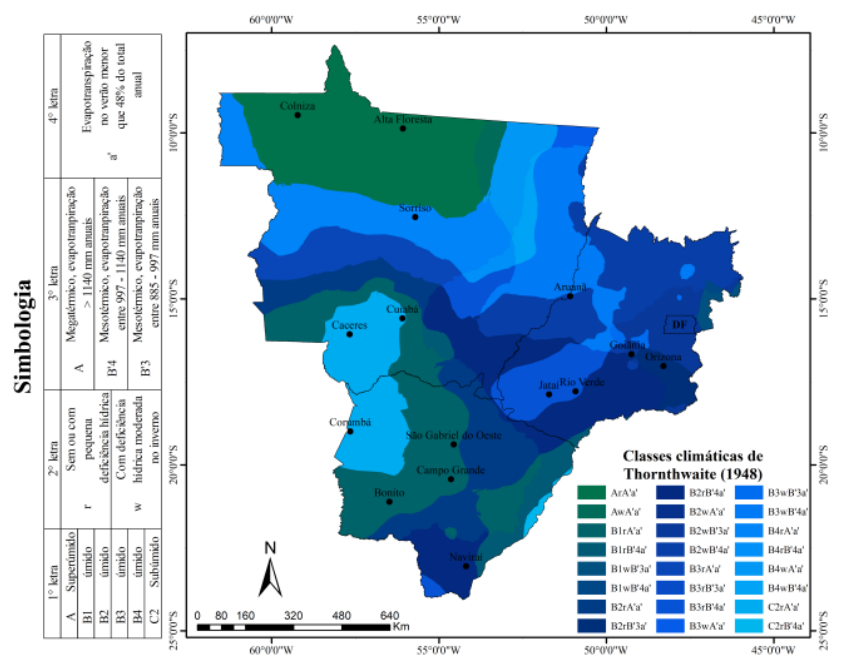

Figure 1. Classificação climática de Thornthwaite (1948) para a região CentroOeste do Brasil.

A combinação entre os elementos extraídos do extrato do BHC explorados na classificação climática de Thornthwaite (1948), permitiu explorar a grande variabilidade climática presente na região Centro-Oeste do Brasil.

\section{Conclusões}

A região Centro-Oeste apresentou 6 tipos climáticos principais e 24 classes climáticas. As classes climáticas de maior predomínio foram ArA'a' e B1rA'a' representando 15,0\% 
e $12,5 \%$ de toda região respectivamente. A classe C2rA'a' apresentou maior predomínio no bioma pantaneiro. Localidades ao norte do Estado do Mato Grosso apresentaram predomínio das classes ArA'a' e AwA'a'.

\section{Referencias}

Baker, B., Diaz, H., Hargrove, W., Hoffman, F. (2010). Use of the Köppen-Trewartha climate classification to evaluate climatic refugia in statistically derived ecoregions for the People's Republic of China. Climatic Change, p. 113-131.

Camargo A. (1971). São Paulo State Water Balance. Bol Inst Agronômico Camp, p. 124.

Cardoso, M. R. D. e Marcuzzo, F. F. N. (2010). Mapeamento de três decênios da precipitação pluviométrica total e sazonal do bioma Pantanal.

CONAB - Companhia Nacional de Abastecimento (2021). Acompanhamento safra brasileira de grãos, v. 8 - Safra 2020/2021, p. 1-108. Disponível em: $<$ https://www.conab.gov.br/info-agro/safras/graos/boletim-da-safra-de-graos $>$.

Djanaguiraman, M., Schapaugh, W., Fritschi, F., Nguyen, H., Prasad, P. V. (2019). Reproductive success of soybean (Glycine max L. Merril) cultivars and exotic lines under high daytime temperature. Plant, cell \& environment, p. 321-336.

Elguindi, N., Grundstein, A., Bernardes, S., Turuncoglu, U., Feddema, J. (2014). Assessment of CMIP5 global model simulations and climate change projections for the 21 st century using a modified Thornthwaite climate classification. Climatic change, p. 523-538.

Krige, D. G. (1951). A statistical approach to some basic mine valuation problems on the Witwatersrand. Journal of the Southern African Institute of Mining and Metallurgy, p. 119-139.

Rolim, G. S., Aparecido, L. E. O. (2016). Camargo, Köppen and Thornthwaite climate classification systems in defining climatical regions of the state of São Paulo, Brazil. International Journal of Climatology, p. 636-643.

Stackhouse, P. W., Westberg, D., Hoell, J. M., Chandler, W. S., \& Zhang, T. (2015). Prediction of Worldwide Energy Resource (POWER)-Agroclimatology methodology-(1.0 latitude by 1.0 longitude spatial resolution). Prediction of Worldwide Energy Resource (POWER)-Agroclimatology methodology-(1.0 latitude by 1.0 longitude spatial resolution).

Tapiador, F. J., Moreno, R., Navarro, A., Sánchez, J. L., García-Ortega, E. (2019). Climate classifications from regional and global climate models: Performances for present climate estimates and expected changes in the future at high spatial resolution. Atmospheric research, p. 107-121.

Thornthwaite C. e Mather J. (1955). The water balance publications in Climatology. DIT Lab Climatol Centerton NJ USA, p. 1-104.

Thornthwaite, C. W. (1948). An approach toward a rational classification of climate. Geographical review, p. 55-94. 